\title{
Experimental investigation of PCM thermal energy storage charge and discharge process with aperiodic (ramp) temperature inputs
}

\author{
Jarosław Karwacki ${ }^{1, *}$, and Roman Kwidziński ${ }^{1}$ \\ ${ }^{1}$ Institute of Fluid Flow Machinery, Polish Academy of Sciences, Fiszera 14, PL-80-231 Gdańsk, Poland
}

\begin{abstract}
In recent years, the use of storages filled with phase-change material (PCM) is increasingly considered. Such design is characterized by a higher density of thermal energy accumulation in comparison with water storages. However, the optimal use of the PCM storages requires a recognition of its dynamic characteristics during the loading and unloading process. This paper presents research aimed at understanding and dynamic description of the heat transfer process in a shell-and-tube thermal energy storage. The experimental test stand and the measurement and control system are described. The investigated storage had a form of a cylindrical tank of $40 \mathrm{dm}^{3}$ volume in which a coil made of pipes with an external diameter of $3.35 \mathrm{~mm}$ was immersed in the PCM. The total heat transfer area was $9.4 \mathrm{~m}^{2}$. A lumped parameter model was used to describe mathematically the storage thermal dynamics. The PCM used was commercially available RT15 material with the heat capacity of $150 \mathrm{~kJ} / \mathrm{kg}$ in the temperature range of $10-17^{\circ} \mathrm{C}$. In the investigations, aperiodic (ramp) temperature inputs were used. The storage tests were carried out for low (12 h) and high $(6 \mathrm{~h})$ speeds of charging and discharging. The amplitude of the input signal and the liquid temperature at the storage inlet were set to include the phase transition interval of the PCM used. The obtained test results allowed to determine the enthalpy as a function of temperature for the whole storage. The experimental results were also used to validate $0 \mathrm{D}$ mathematical model of the heat storage.
\end{abstract}

\section{Introduction}

Heat storage with phase change material (LTES - Latent Thermal Energy Storage) has been used in refrigeration and air conditioning applications for many years. Mostly known area of LTES application is the peak demand management in commercial buildings [1]. In this case, the ice-banks system (TES with water) is used to reduce the operating costs. The use of other phase change materials (PCM) in low temperature applications is also increasingly considered. In active peak load shifting systems, the correct, optimal operation of the heat storage using PCM requires not only the selection of appropriate material but also appropriate control of the loading and unloading process. The mathematical modelling is often used for the optimization of the cooling system's operation [1]. In many cases, the proper design of the automatic control system is limited by the knowledge of the control object model. In this case, a specific form of the mathematical model of the heat store must also be adopted. It turns out that creating a model satisfactorily reflecting the behaviour of the PCM storage is not trivial. This is mainly due to the peculiar characteristics of changes in the properties of phasechange materials in the area of phase transition.
The authors, in earlier works, conducted a theoretical analysis of the feasibility of using a storage with phase change material to support the photobioreactor cooling system for the production of the algae [2] and to cooperate with an adsorption chiller supply from district heating system [3]. The analyses show that the effective use of LTES requires the use of non-standard methods for control the loading and unloading process. Planning the implementation of the mentioned above systems on a semi-industrial scale, an attempt was made to create their own regulation based on Model Based Control (MBC) algorithm. Typically, in such cases, lumped parameter model is used. Due to the non-linear nature of the process as well as the frequent occurrence of hysteresis and subcooling during the phase transition of typical PCM materials, the creation of the correct LTES model turned out to be the biggest problem. In this paper the preliminary steps are taken to develop an experimental procedure to calibrate and verify the dynamic, lumped parameter LTES model.

\section{Experimental identification of dynamic systems}

During the process of constructing a TES, its geometry, the shape of the heat exchange surface and the

\footnotetext{
Corresponding author: jkarwacki@imp.gda.pl
} 
thermophysical properties of construction materials are known. In most cases, the thermo-physical properties of PCM materials used for heat accumulation are also known. Using this information it is possible to develop more or less comprehensive dynamic model of TES/LTES [2, 3, 4].

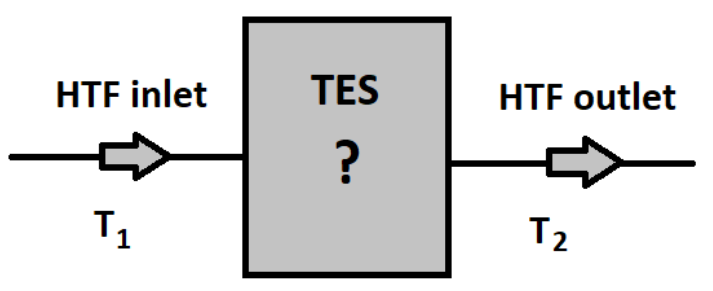

Fig. 1. Experimental identification of dynamic TES systems: $T_{1}, T_{2}$ are heat transfer fluid input and output temperatures, respectively.

In the general case, there is no enough information to create a dynamic model of a heat storage accurately describing the behaviour of the object. In particular, this applies to lumped parameter models involving significant simplifications. One of the ways to improve the prediction of working parameters is the experimental calibration of the models. This is accomplished through a sequence of actions aimed at identification of the dynamic system [5]. The experimental verification of the dynamic model assumes that for a precisely defined input signal, there are characteristic changes in the output signal. This behaviour is related to the uniquely defined dynamic characteristics of the object. By analysing the input and output signal, it is possible to draw conclusion about the dynamics of the object.

In the case of the analysed TES/LTES (Fig. 1), this is reduced to the analysis of heat transfer fluid (HTF) outlet temperature $T_{2}$ changes depending on the inlet temperature $T_{1}$ profile. The active method adopted in this work assumes an experimental identification of the model based on the reaction of the object to a strictly defined test signal. Most often used are simple nonperiodic test signals as: step function, ramp function, rectangular pulse, trapezoidal pulse. In some cases, periodic signals, usually sinusoidal, are also used in the active identification process. However, it is associated with much higher workload of the experimental tests.

To gain thermophysical properties of phase change materials, different experimental methods are available [6]. The most popular is DSC (differential scanning calorimetry) technique using multi step function or ramp function to measure the specific heat and latent heat of PCM. The amount of sampling mass used in DSC is less than $50 \mathrm{mg}$. Despite of this, similar testing signals are used in laboratory scale experiments to obtain thermal capacity of LTES.

The most frequent measurement technique is based on a sudden change of inlet HTF temperature (step function) [7]. In such experiments, the input temperature of the heat transfer fluid is instantaneously set at the desired value, while the output temperature evolution is recorded. The range of inlet temperature change is set to include the phase transition interval of the used PCM. Because of the installation thermal inertia, the pure step function test is difficult to carry out. One of the ways is to use two separate storage vessels holding HTF at two different temperatures [7]. In a closed HTF cycle, the step change of the set HTF inlet temperature does not cause sudden answer. Instead, sometimes it causes a fluctuation of inlet temperature or the profile of the temperature changes is not sharp enough $[8,9]$. In some cases it has significant influence on the overall quality of experimental results.

In literature, there are a lot off LTES experimental analyses in various dynamics conditions [7, 8, 9, 10]. Sometimes the LTES is installed as a part of production line [10] and system is tested under real operating conditions. For the most part of these published experimental analyses, the attention is focused on determining energy stored by the TES under full and/or partial capacity loads. As a result of the tests, charging and discharging rates are also calculated. This type of analysis could give some information about heat transfer dynamic in thermal energy storage. However, in none of these papers systematic methodology of the dynamic characteristic determination is presented.

\section{Methodology}

\subsection{Experimental setup}

An experimental setup was developed and built to investigate dynamic characteristics of different thermal energy storages.

The layout of the experimental setup is shown in Fig. 2. Two different loops, separated by the heat exchanger 4, can be identified. The first loop (left of Fig. 2), is a typical compressor refrigeration cycle. To achieve more stable working conditions, typical thermostatic expansion valve was replaced by electronic device 3. An own algorithm of valve regulation allowed to achieve very small fluctuation of the working parameters during tests. In the second loop, water was used as the heat transfer fluid. To achieve fast temperature response of the system, amount of water was minimized. Water chilled in the evaporator is pumped to TES container 9 by the pump 6. To achieve the set inlet temperature of water, electric heater 7 was used. To minimize the fluctuations of inlet temperature, electric heater was equipped with the precise singlephase power controller JUMO TYA-201.

In the key points of experimental stand, $\mathrm{K}$ type thermocouple sensors were installed. Four additional temperature sensors were installed inside the storage tank between HTF tubes. These thermocouples, located at equal distances of $100 \mathrm{~mm}$ along the container, were used to measure PCM temperature. To achieve fast temperature response, the sensors with $1 \mathrm{~mm}$ shield diameter were used. All thermocouples were calibrated and tested before installation using the Beamex MC6 calibrator, the DRUCK DB-150 calibration furnace and the reference temperature sensor PT100 ISOTECH. After this process, the precision of the thermocouples was $\pm 0.1^{\circ} \mathrm{C}$ for $0^{\circ} \mathrm{C}$ and $\pm 0.15^{\circ} \mathrm{C}$ for $25^{\circ} \mathrm{C}$. Special attention was made to accurately determine temperature 
difference between HTF inlet and outlet of the TES container. The accuracy of this parameter was better than $\pm 0.05 \mathrm{~K}$.

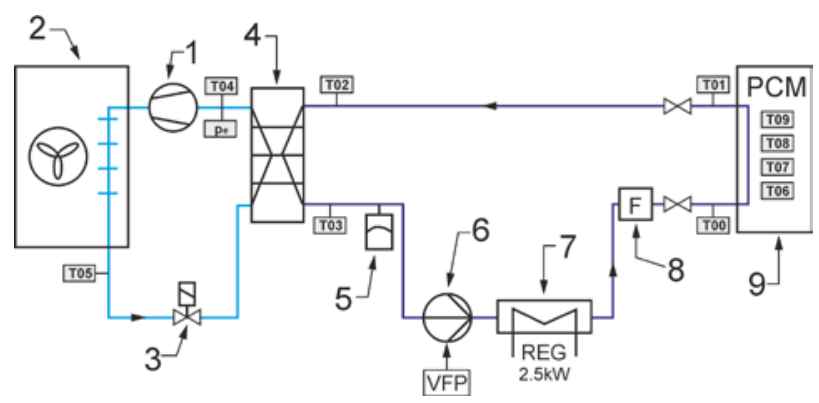

Fig. 2. Layout of experimental setup: 1 - compressor, 2 - condenser, 3 - expansion valve, 4 - evaporator, 5 expansion tank, 6 - circulating pump, 7 - heater, 8 flowmeter, 9 - LTES.

A heat transfer fluid flow rate was kept constant by regulating rotating speed of the circulating pump. The value of flow rate in all cases was $200 \pm 10 \mathrm{~kg} / \mathrm{h}$. Water mass flow rate was measured with accuracy $2.5 \%$ by vortex flow meter Kobold DVZ-1104G4C34P.

The photo of the experimental setup is shown in Fig. 3. The TES container with PCM is visible in the foreground on the left side.

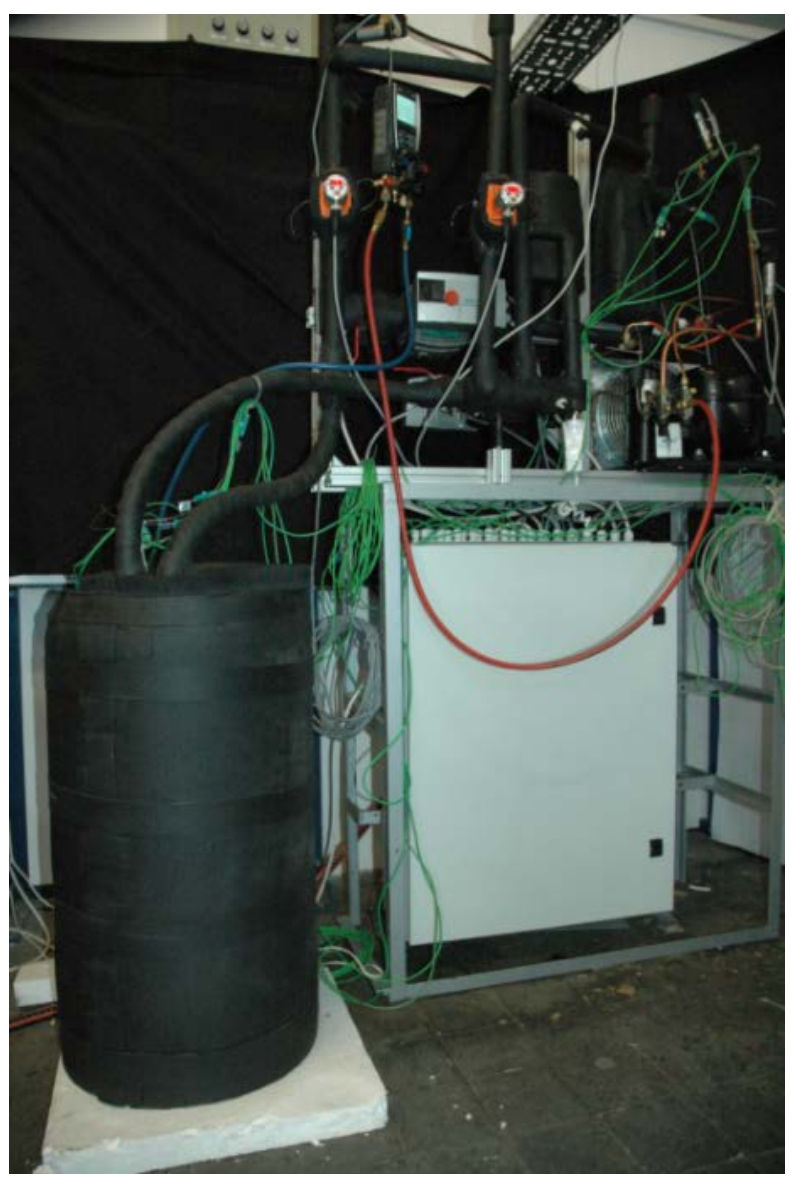

Fig. 3. Photo of the stand dedicated to investigation of the dynamic characteristics of LTES.

The data acquisition facility was based on National Instrument systems and software. NI cRIO 9025 controller was used as a main part of data acquisition and regulation system. This system logs all main parameters and controls the valves, pumps, electric heaters and safety system. During the experiments the real time measurements are shown on the computer screen while all measured data are stored in a data file.

\subsection{Construction of LTES container}

Often in storage tanks construction, typical designs known for heat exchangers are used [9]. In some cases commercial heat exchangers are considered for use as PCM thermal storage systems [8]. In the cases when PCM is encapsulated, special construction of LTES container is designed. In all types of geometry, due to low thermal conductivity of phase change materials, the key parameter is the ratio of heat transfer area to the PCM volume.

In this study, the main idea of the LTES design process was to create a not too expensive construction using elements available on the market. To form the heat transfer surface between PCM and heat transfer fluid, typical capillary tube mats were used. Such mats are applied in housing for wall and ceiling heating and cooling systems.

Internal design of the investigated LTES container is presented in the Fig. 4. Because of the limited capillary tubes bending radius, usable volume for the PCM is placed between two concentric tubes. The essential parameters of the construction are presented in Table 1. For the designed construction, the ratio of heat transfer area to PCM volume is about $0.15 \mathrm{~m}^{2} / \mathrm{dm}^{3}$. This value is comparable to the best constructions described in literature [8].

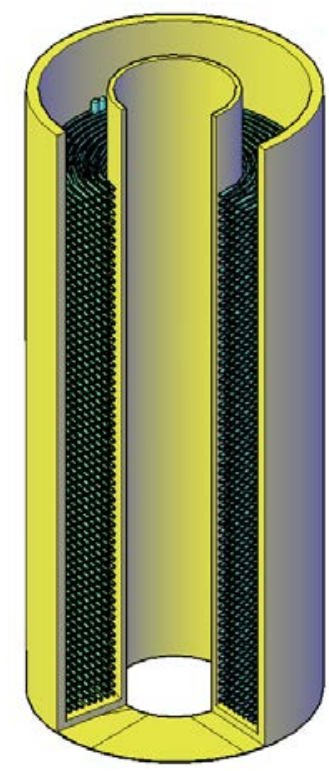

Fig. 4. View of TES container geometry and heat transfer surface. 
Table 1. Summary of principal geometrical and thermophysical properties of the LTES container.

\begin{tabular}{|l|c|}
\hline \multicolumn{2}{|c|}{ Two concentric tubes of cylindrical vessel } \\
\hline material & polyethylene \\
\hline mass $[\mathrm{kg}]$ & 0.43 \\
\hline insulation & Armaflex \\
\hline \multicolumn{2}{|c|}{} \\
\hline material & polypropylene \\
\hline outer diameter $[\mathrm{mm}]$ & 3.35 \\
\hline wall thickness $[\mathrm{mm}]$ & 0.5 \\
\hline spacing between the tubes $[\mathrm{mm}]$ & 10 \\
\hline thermal conductivity $[\mathrm{W} / \mathrm{m} \cdot \mathrm{K}]$ & 0.24 \\
\hline specific heat $[\mathrm{J} / \mathrm{kg} \cdot \mathrm{K}]$ & 2000 \\
\hline mass $[\mathrm{kg}]$ & 1.26 \\
\hline \multicolumn{2}{|c|}{ LTES } \\
\hline heat transfer area $\left[\mathrm{m}^{2}\right]$ & 4.097 \\
\hline PCM mass $[\mathrm{kg}]$ & 27.86 \\
\hline
\end{tabular}

\subsection{Theoretical analysis of charge/discharge capacity of TES}

In contrast to laboratory test stand, industrial installation have a much smaller number of temperature sensors. They are placed only at the most important points of the cycle. In most cases, temperature measurement of the storage material is difficult or impossible. This is particularly important in experimental investigation of commercial TES. In this case, nothing is known about the internal structure of storage container and the properties of accumulating material. It should be treated as "black box". From this reason, it was assumed that all storage characteristics should be investigated and presented as a function of HTF temperature.

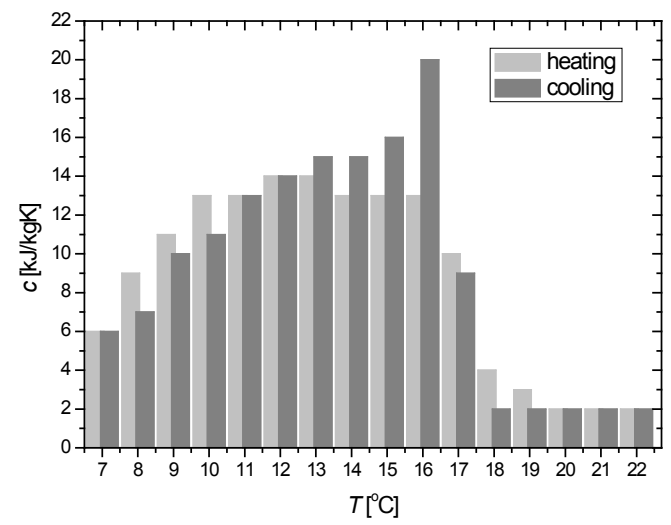

Fig. 5. Effective specific heat $\mathrm{c}$ distribution as a function of PCM temperature $T$ for the phase change material RUBITHERM RT15 [manufacturer data].

To analyse the impact of the charging/discharging dynamics on effective energy storage, the base characteristics of LTES should be estimated. Effective specific heat distribution as a function of HTF temperature, estimated in steady-state conditions was assumed to be such base characteristic. It was calculated using PCM manufacturer data (Fig. 5) and TES container data (Table 1). It was assumed that in steadystate conditions HTF and PCM temperatures are the same.

Calculated LTES effective specific heat distribution, as a function of HTF temperature is presented in the Fig. 6. Based on manufacturer data, PCM specific heat in solid state is equal $2 \mathrm{~kJ} / \mathrm{kg}$ but nothing is known about the lower temperature of phase change process onset. For initial analysis it was assumed that below $7^{\circ} \mathrm{C} \mathrm{PCM}$ is in solid state.

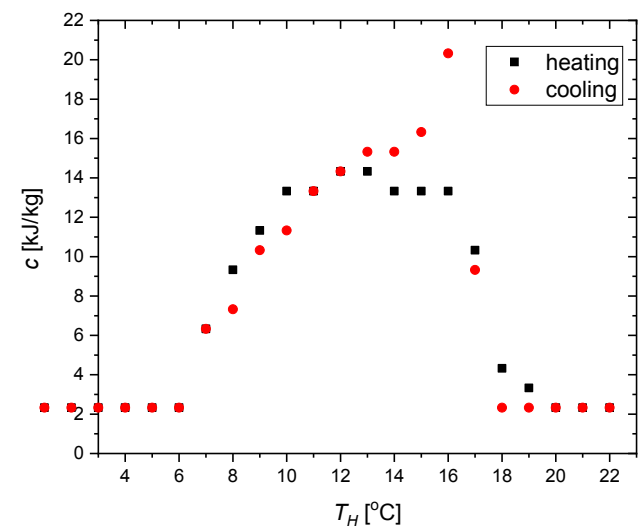

Fig. 6. Calculated LTES effective specific heat $c$ distribution as a function of average HTF temperature $T_{H}$ for heating and cooling process.

\subsection{Computational model of LTES}

As it was mentioned earlier, the main aim of the work is to design the MBC algorithm for cooling systems with LTES. The essential point of planned activities is to design mathematical model of the heat storage. The model should properly estimate outlet temperature of HTF based on inlet temperature. Below is described numerical model with assumption that the construction of the TES container is known. In next steps it is planned to design model when LTES is treated as "black box".

The numerical model of the heat storage describes heat transfer and accumulation between the HTF, the PCM and the material of the tubes' walls as well as the heat transfer to or from the surroundings [3]. Balance equations for each material accumulating heat in the storage can be written in the form:

HTF:

$$
M_{H} c_{H} \frac{d T_{H}}{d \tau}=\dot{m}_{H} c_{H}\left[T_{H 1}(\tau)-T_{H 2}(\tau)\right]+\frac{T_{W}(\tau)-T_{H}(\tau)}{R_{H W}}(1)
$$

PCM:

$$
M_{P} c_{P}\left(T_{F}\right) \frac{d T_{P}}{d \tau}=\frac{T_{W}(\tau)-T_{P}(\tau)}{R_{P W}}+\dot{Q}_{A}
$$

capillary wall:

$$
M_{W} C_{W} \frac{d T_{W}}{d \tau}=\frac{T_{P}(\tau)-T_{W}(\tau)}{R_{P W}}+\frac{T_{H}(\tau)-T_{W}(\tau)}{R_{H W}} .
$$

where $M$ is mass, $c$ is the specific heat or effective specific heat (for PCM), $T$ is the average temperature, $\dot{m}_{H}$ is the HTF mass flow rate, $\dot{Q}_{A}$ is the transfer of 
thermal energy to/from the ambient. In the notation, subscript have the following meaning: $H$ for HTF, $P$ for PCM, $W$ for capillary wall, 1 for inlet parameter, 2 for outlet parameter.

In the above equations, heat transfer from the liquid zones and the ambient was treated as purely convective. In the remaining zones only conductive heat transfer was assumed. Thermal resistance between the PCM and tube wall and between the tube wall as well as HTF can be written as, respectively:

$$
\begin{aligned}
& R_{P W}=\frac{\delta_{P}}{\lambda_{P} A_{P}}+\frac{\delta_{W}}{2 \lambda_{W} A_{P W}} \\
& R_{H W}=\frac{1}{\alpha_{H} A_{H}}+\frac{\delta_{W}}{2 \lambda_{W} A_{H W}}
\end{aligned}
$$

where $\delta$ is the wall thickness, $\lambda$ is the thermal conductivity, $A$ is the heat transfer area.

The convective heat transfer coefficient for HTF is given by the relation:

$$
\alpha_{H}=\frac{N u \lambda_{H}}{d}
$$

For the analysed geometry, the length of tubes is much larger than their inner diameter and the Reynolds number is very low. Thus, it was assumed after [11] that Nusselt number value in thermal, fully developed laminar flow can be taken as $N u=4.364$.

\subsection{Test procedure}

In the experimental investigations, the ramp type HTF inputs temperature changes were used. This type of aperiodic test signal was selected to obtain precisely defined dynamic input conditions. The experimental equipment allow to exactly control changes on the HTF inlet temperature in wide range of rates set in.

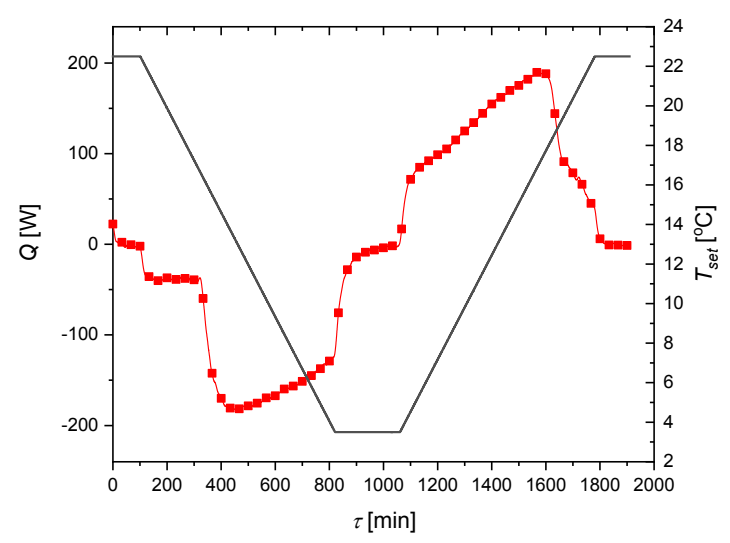

Fig. 7. Experimental data of a cooling and heating process for the case with constant $T_{\text {set }}$ slope equal to $39.9 \mathrm{~min} / \mathrm{K}: T_{\text {set }}$ - set inlet temperature of HTF (solid black line), $\dot{Q}$ - heat flow rate (symbol red line).

The run of test procedure is presented in Fig. 7 which shows time profiles of the temperature $T_{\text {set }}$ and transferred heat flow rate $\dot{Q}$. The initial temperature was set at $22.5^{\circ} \mathrm{C}$. After reaching the steady-state condition, system goes into the cooling state at a constant rate of $T_{\text {set }}$ change. The final temperature of this process was $3.5^{\circ} \mathrm{C}$. After reaching the steady-state condition, system goes into the heating state at the same constant rate of $T_{\text {set }}$ change as previously. The test procedure ended when the set temperature reached $22.5^{\circ} \mathrm{C}$ again. The amplitude of the input signal and the liquid temperature at the storage inlet were selected to include the phase transition interval of the used PCM.

Rate of heat losses to the ambient $\dot{Q}_{A}$ was estimated experimentally as a function of differences between ambient and HTF temperature. Calculated overall heat transfer coefficient is equal to $k=1.272 \mathrm{~W} /\left(\mathrm{m}^{2} \cdot \mathrm{K}\right)$. Heat losses have been taken into account in experimental data analysis.

As it was mentioned earlier, the control system was able to follow accurately the set profile of the temperature. It can be seen in Fig. 8 where the difference between the set and the measured temperature of HTF is shown. During test run test the highest differences of these temperatures occurred when the system changed working mode (cooling/heating/stable-state). During the cooling highest differences of these temperatures occurred when the phase change process has begun, during heating when it has ended.

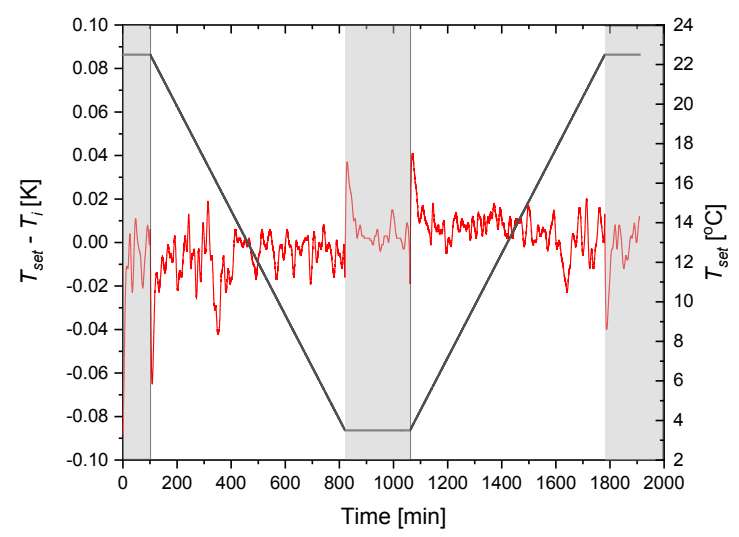

Fig. 8. Difference between the set temperature $T_{\text {set }}$ and the measured temperature $T_{H I}$ (solid red line) as a function of time - experimental data of a cooling and heating process for the case with constant $T_{\text {set }}$ slope equal to $37.9 \mathrm{~min} / \mathrm{K}$.

\section{Results and discussion}

The storage tests were carried out for low (12 h) and high $(6 \mathrm{~h})$ speeds of charging and discharging process. It corresponds to the inlet temperature $T_{\text {set }}$ constant slope equal to $37.9 \mathrm{~min} / \mathrm{K}$ and $18.95 \mathrm{~min} / \mathrm{K}$ respectively. For both cases, enthalpy as a function of HTF temperature is presented in Fig. 9. It can be seen for each case that, the phase change temperature ranges during cooling and heating are different. It means that there is an important hysteresis effect for these type of PCM. On the characteristics, the part where the PCM is in a solid state can be easily distinguished, it is above the temperature of about $17^{\circ} \mathrm{C}$. Enthalpy profile analysis does not allow to determine the bottom limit phase transition temperature unambiguously. This may be due to the fact that 
experimental tests are carried out for the whole container, not for PCM only. Another reason may be in the specific properties of the material used.

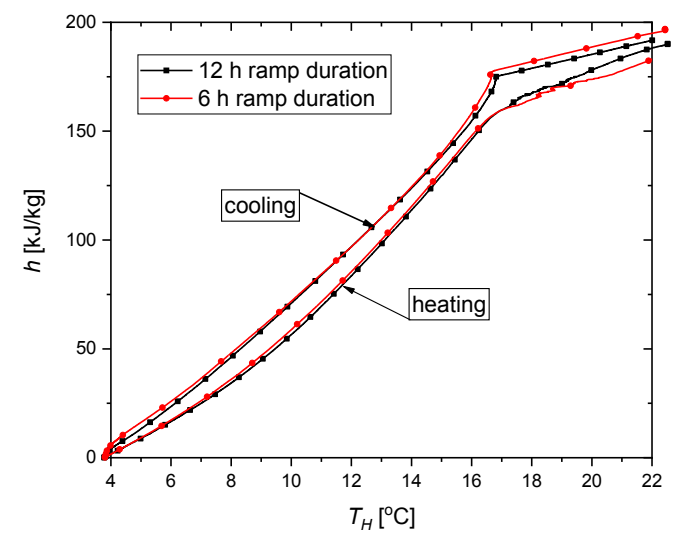

Fig. 9. Enthalpy as a function of average HTF temperature for long (12 h) and short $(6 \mathrm{~h})$ durations of heating and cooling process.

To analyse the impact of dynamics characteristics of the charging/discharging process on the heat storage, effective specific heat $c$ distributions as a function of average HTF temperature $T_{H}$ were calculated. For the experimental data, specific heat is defined as:

$$
c=\frac{h^{i}-h^{i-1}}{T_{H}^{i}-T_{H}^{i-1}}
$$

where $i$ is the samples number.

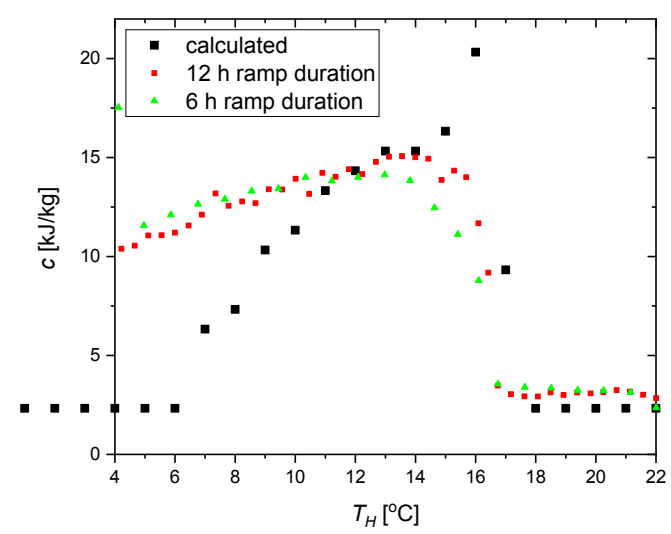

Fig. 10. The calculated (Fig. 6) and measured effective specific heat $c$ distribution as a function of average $\mathrm{HTF}$ temperature $T_{H}$ for the cooling process.

For the cooling (charging) process, comparison between the calculated (see Fig. 6) and measured values is presented in Fig. 10. It can be seen in the liquid state region (temperature range between $22^{\circ} \mathrm{C}$ and $17^{\circ} \mathrm{C}$ ) that the measured effective specific heat is slightly higher than the one calculated with manufacturer data for PCM properties. Its value is independent of the speed of temperature change. When the phase change process begins it can be seen that charging process is different for the two measured cases. Namely, in the temperature range between $17^{\circ} \mathrm{C}$ and $12^{\circ} \mathrm{C}$ the effective specific heat values are smaller for the higher rate of temperature changes. This is related to the smaller amount of accumulated heat during cooling process. Comparing with the calculated values, there is no increase value of $c$ for the temperature of $16^{\circ} \mathrm{C}$. Below the $12^{\circ} \mathrm{C}$, the values of $c$ are similar for both ramp slopes. In this range calculated and experimental values of the effective specific heat differ significantly.

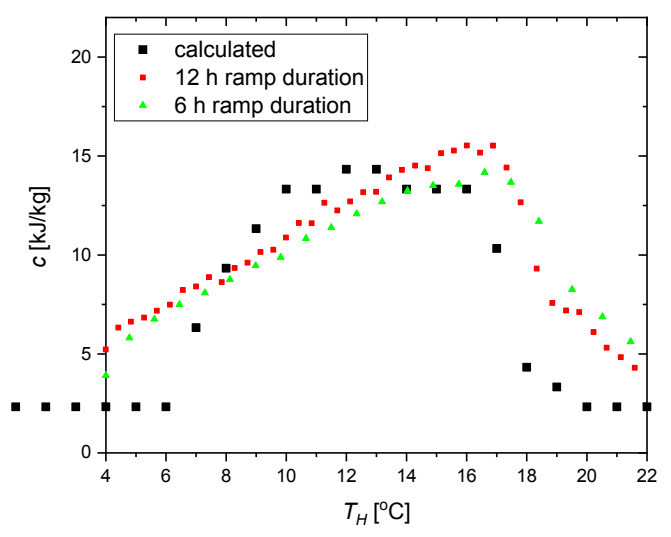

Fig. 11. The calculated (Fig. 6) and measured effective specific heat $c$ distribution as a function of average HTF temperature $T_{H}$ for the heating process.

For the heating (discharging) process comparison between calculated and measured values is presented in Fig. 11. As it was mentioned above, it is not possible to show the interval in which the material is in a solid state. It can be seen that in the range between $4^{\circ} \mathrm{C}$ and about $9^{\circ} \mathrm{C}$ that the measured effective specific heat is significantly greater than the calculated one. The same relationship holds for temperatures above the $14^{\circ} \mathrm{C}$. In the temperature range between $9^{\circ} \mathrm{C}$ and $14^{\circ} \mathrm{C}$, the measured $c$ value is higher than the calculated. It can be seen that effective specific heat for faster $(18.95 \mathrm{~min} / \mathrm{K})$ discharging process is lower up to the temperature equal to $14^{\circ} \mathrm{C}$. Above this temperature $c$ is higher for faster discharging process.

It can be seen that for the both process directions, the difference between the calculated and experimental value of effective specific heat for LTES is significant. In comparison, the impact of ramp duration on this difference is significantly smaller.

\section{Validation of theoretical model}

One of the important tasks of the present work was to find the method to refine and validate the lumped parameter model describing thermal energy storage. This method should be useful for TES with phase change material. The result of the model validation and the tips for its validation are presented below.

The input data for modelling process come from the experimental investigation. They are: inlet temperature of heat transfer fluid $T_{H 1}$, mas flow rate $\dot{m}_{H}$, effective specific heat (Fig. 6) and geometrical and thermo- 
physical properties of the LTES container. Experimental and theoretical result of heat flow rate for the case with $12 \mathrm{~h}$ ramp duration is presented in Fig. 12. The directions of the charging/discharging process are indicated by arrows. It can be seen that the main difference of these profiles is visible at in the end of the cooling process (range between $8^{\circ} \mathrm{C}$ and $3.5^{\circ} \mathrm{C}$ ) and at the end of the heating process (range between $18^{\circ} \mathrm{C}$ and $22.5^{\circ} \mathrm{C}$ ). Further analysis here will focus on the range from $4^{\circ} \mathrm{C}$ to $22^{\circ} \mathrm{C}$, omitting the transient states at the ramp lead in and out.

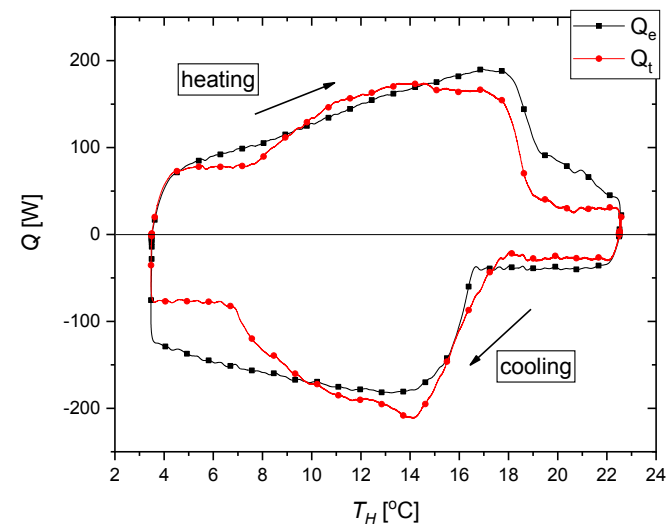

Fig. 12. The calculated $\left(\dot{Q}_{t}\right)$ and measured $\left(\dot{Q}_{e}\right)$ heat flow rate as a function of average HTF temperature $T_{H}$ for the case with $12 \mathrm{~h}$ ramp duration.

The main parameter obtained from the model is the outlet temperature of heat transfer fluid $T_{H 2 t}$. To assess accuracy of the modelling process, the difference between the measured $T_{H 2 e}$ and theoretical $T_{H 2 t}$ temperature is calculated. They are presented in Fig. 13 and Fig. 14 for both cases investigated experimentally.

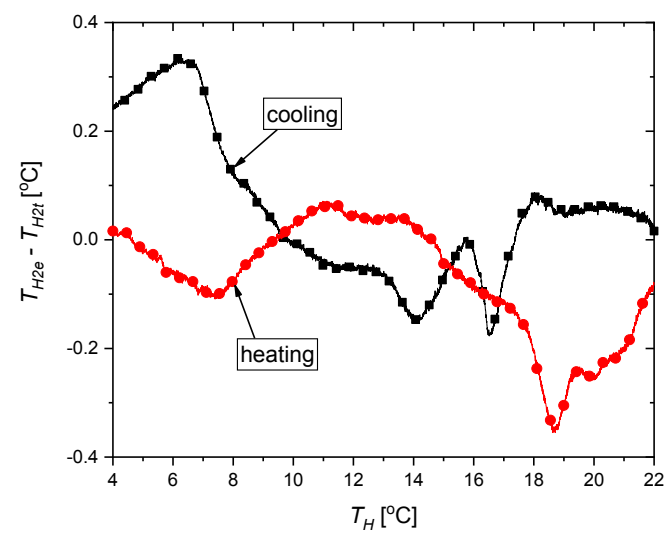

Fig. 13. Difference between the measured $T_{H 2 e}$ and calculated $T_{H 2 t}$ temperature as a function of average HTF temperature $T_{H}$ (cooling and heating process for the case with constant $T_{\text {set }}$ slope equal to $37.9 \mathrm{~min} / \mathrm{K}$ ).

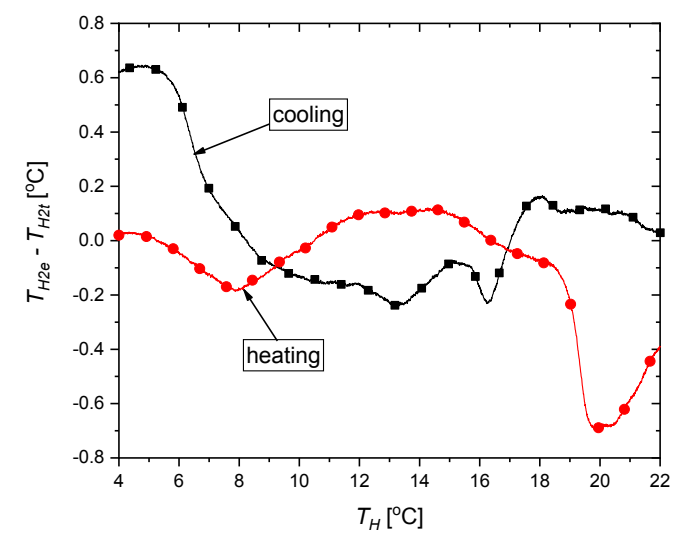

Fig. 14. Difference between the measured $T_{H 2 e}$ and calculated $T_{H 2 t}$ temperature as a function of average HTF temperature $T_{H}$ (cooling and heating process for the case with constant $T_{\text {set }}$ slope equal to $18.95 \mathrm{~min} / \mathrm{K}$ ).

In analogy to the results shown in Fig. 12, it can also be seen that for both cases the main difference of these profiles is visible at the end of cooling process (range between $8^{\circ} \mathrm{C}$ and $3.5^{\circ} \mathrm{C}$ ) and at the end of heating process (range between $18^{\circ} \mathrm{C}$ and $22.5^{\circ} \mathrm{C}$ ). The incompatibility between the calculated and measured results increased by about $50 \%$ for the higher rate of cooling/heating process, compared to case with the lower rate.

\section{Conclusions}

In this study, the experimental recognition procedure of thermal energy storage dynamic characteristics was presented for the loading and unloading process. The constant rate of inlet temperature change (i.e. ramp) was chosen as a test signal. Two cases with $12 \mathrm{~h}$ and $6 \mathrm{~h}$ ramp duration were investigated. The tested storage had a form of a cylindrical tank of $40 \mathrm{dm}^{3}$ volume in which a coil made of pipes with an external diameter of $3.35 \mathrm{~mm}$ was immersed in the PCM. The PCM used was commercially available RUBITHERM RT15. The experimental test stand, the measurement and control systems and test procedure were described. Also the mathematical OD model of the thermal energy storage was proposed.

The main conclusions of experimental investigation and theoretical analysis are:

- the applied measurement procedure allowed to perform measurements with high accuracy;

- the use of manufacturer's data leads to large errors in the model results;

- the temperature range that could be investigated in the experiment did not allow to analyse the PCM properties in the solid state;

- for the two investigated ramp durations, the differences in storage heat capacity are small but noticeable;

- thermal dynamics of the investigated storage is different for the cooling and heating process. 
As a future work, it is planned to:

- prepare own, baseline characteristic of effective specific heat capacity for quasi static states (i.e. much longer ramps or unit steps);

- investigate more extensively the changes in the dynamics of the charging/discharging process, using shorter times (which requires a replacement of the refrigeration system on the experimental stand);

- investigate more extensively the PCM characteristics at low temperatures (requires a modification of the refrigeration system);

- test partial charging and discharging;

- test the input signals other than the ramp (also periodic);

- validate the theoretical model in a wide range of the storage charging and discharging speeds.

\section{References}

1. Y. Sun, S. Wang, F. Xiao, D. Gao, Peak load shifting control using different cold thermal energy storage facilities in commercial buildings: A review. Energy Conversion and Management 71 (2013), 102-114

2. J. Karwacki, R. Kwidziński, A. Tomaszewski, A. Cenian, J. Großman, S. Matthes, M. Lackowski, Usage of PCM thermal energy storage in the temperature stabilizaton system of bioreactor for algae cultivation [in Polish]. Proc. XLIX Dni Chłodnictwa (2017), 107-125

3. J. Karwacki, R. Kwidziński, Theoretical analysis of a latent thermal energy storage system with an adsorption chiller. Polska Energetyka Słoneczna, No 1-4/2016, 59-64

4. J. Bony, S. Citherlet, Numerical model and experimental validation of heat storage with phase change material. Energy and Buildings 39 (2007), 1065-1072
5. R. Isermann, M. Münchhof, Identification of Dynamic Systems. An Introduction with Applications (Springer, Berlin, 2011)

6. L.F. Cabeza, C. Barreneche, I. Martorell, L. Miró, S. Seri-Bey, M. Fois, H.O. Paksoy, N. Sahan, R. Weber, M. Constantinescu, E.M. Anghel, M. Malikowa, I. Krupa, M. Delgado, P. Dolado, P. Furmanski, M. Jaworski, T. Haussmann, S. Gschwander, A.I. Fernández, Unconventional experimental technologies available for phase change materials (PCM) characterisation. Part 1. Thermophysics properties. Renewable and Sustainable Energy Reviews 43 (2015), 1399-1414

7. T. Nuytten, P. Moreno, D. Vanhoudt, L. Jespers, A. Solé, L.F. Cabeza, Comparative analysis of latent thermal energy storage tanks for micro-CHP systems. Applied Thermal Engineering 59 (2013), 542-549

8. M. Medrano, M.O. Yilmaz, M. Nogués, I. Martorell, J. Roce, L.F. Cabeza, Experimental evaluation of commercial heat exchangers for use as PCM thermal storage systems. Applied Energy 86 (2009), 20472055

9. A. Gil, E. Oró, L. Miró, G. Peiró, A. Ruiz, J.M. Salmerón, L.F. Cabeza, Experimental analysis of hydroquinone used as phase change material (PCM) to be applied in solar cooling refrigeration. International Journal of Refrigeration 39 (2014), 95103

10. M. Grozdek, B. Halasz, T. Ćurko, V. Soldo, Experimental investigation of an ice-bank system performance. $3^{\text {rd }}$ IIR Conference on Thermophysical Properties and Transfer Processes of Refrigeration, (2009)

11. H.D. Baehr, K. Stephan, Heat and Mass Transfer (Springer, Berlin, 2006) 